\title{
Intermediate Term (3-6 Years Post Surgery) Outcome of Keratoprosthesis in 5 Nigerian Eyes
}

\author{
Joseph Momodu Waziri-Erameh MB, BS, FMC (Oph) ${ }^{1}$; Afekhide Ernest Omoti MB,BS, FMC \\ (Oph) FWACS, FICS ${ }^{1}$; Chinyere Nnenne Pedro-Egbe MBBS, FMC (Oph) ${ }^{2}$ \\ ${ }^{1}$ Department of Ophthalmology, University of Benin Teaching Hospital. PMB 1111, Benin City, Nigeria \\ ${ }^{2}$ Department of Ophthalmology, University of Port Harcourt Teaching Hospital, Port Harcourt, Nigeria
}

\section{A BStract}

Objective: The aim of this study is to report on the intermediate (3-6 years post surgery) outcome of keratoprosthesis implant surgery in Nigerian eyes.

Methods: This is a descriptive study of 5 eyes of 5 consecutive Nigerian patients that had keratoprosthesis at University of Benin Teaching Hospital and DDS Eye Surgery, Benin City, between February 1994 and May 1995. The 5 eyes were followed up for 3-6 years.

The visual acuity and observed complications were monitored in each eye.

Results: All the patients in this study were male, with an age range 30 to 76 years and a mean age of 42 years. Preoperatively, one eye had corneal decompensation following cataract extraction, while the other 4 eyes had scarred and vascularized cornea from various causes; all 5 eyes had light perception $(L P)$ vision pre-operation. Post-operatively, the 5 eyes had $V A$ ranging from $6 / 60$ to NLP, after a variable follow-up period of 3-6 years. Complications included development of tough vascularized retroprosthetic membrane (4 eyes) and infective endophthalmitis in one eye.

Conclusion: The intermediate-term outcome of keratoprosthesis surgery in Nigerian eyes shows that it is unsuitable, largely because of the problem of retroprosthetic membrane.

Key words: keratoprosthesis, retroprosthetic membrane, cornea

\section{INTRODUCTION}

Keratoprosthesis is an artificial cornea-lens complex that combines the optical properties of the crystalline lens and the cornea. Surgery is the last resort and only option for severely a damaged cornea and anterior segment, where keratoplasty has no chance of success. ${ }^{1,2}$ The concept of using keratoprosthesis in eyes with corneal blindness has been known for more than 200 years. $^{3}$ Guillaume Pellier de Quengsy carried out the first keratoprosthesis experiment in 1789. ${ }^{4}$ Corneal disease is the cause of blindness in about 10 million people worldwide, out of which a significant percentage have light perception vision. A large percentage of these 10 million blind people are in the less developed world, where the non-transparent cornea represents an important percentage of the causes of blindness in the incurable blind. ${ }^{5}$ In Nigeria and elsewhere in the developing world, the nontransparent cornea is a common cause of blindness ${ }^{6}$ made more serious by the lack of donor corneas. Corneal graft (penetrating keratoplasty) has been performed on a few sporadic cases with corneas imported from abroad. Apart from the problems involved in procuring donor cornea from abroad or setting up cornea banks, many of those blind from corneal disease/pathology will not have successful corneal graft. This is because the nature of corneal disease in Nigeria generally results in very scarred and vascularized cornea; while the anterior segments may be disorganized from trachoma, chemical burns, and the indiscriminate use of harmful herbal cocktails on the eyes, ${ }^{7}$ to mention a few.

Between 1994 and 1995, the first keratoprosthesis surgery in Nigeria was carried out on 5 eyes (Worst-Singh keratoprosthesis). Until this time, optical iridectomy was the only method utilized to remove corneal opacity, however, this procedure was not very helpful if the corneal opacity was large. ${ }^{8}$ The authors of this report attempted to address the situation using keratoprosthesis surgery as developed by Worst-Singh.

In 2001, the preliminary report on the first five eyes that had keratoprosthesis in Nigeria was published. ${ }^{9}$ The shortterm findings were very encouraging, and the early-term complications were largely satisfactory and manageable. This article is on the intermediate-term (3-6 years post surgery) outcome of these five eyes after the keratoprosthesis surgery.

${ }^{*}$ Correspondence: Dr. Joseph Momodu Waziri-Erameh, Department of Ophthalmology, University of Benin Teaching Hospital, PMB 1111, 


\section{MAterial, Methods AND PATIENTS}

This is a descriptive, non-comparative case study of 5 eyes of 5 Nigerians who had Worst-Singh keratoprosthesis surgery at the University of Benin Teaching Hospital (UBTH) and DDS Eye Surgery Benin City between February 1994 and May 1995. The procedure was performed under local anaesthesia (retrobulbar with $5 \mathrm{mls}$ of $2 \%$ lidnocaine). All the 5 eyes were operated on by one consultant ophthalmologist, assisted by other consultants and resident ophthalmologists. Informed consent was obtained from all 5 patients; approval was also obtained from the UBTH Ethical Committee. The materials and design of the Worst-Singh keratoprosthesis and the surgical procedures are as developed and described by WorstSingh and van Andel. ${ }^{5}$ The Worst-Singh design minimized complications such as extrusion, leakage, melting away, epithelial down growth and endophthalmitis. It was considerably less expensive than other comparable designs of keratoprosthesis available.

\section{Selection criteria}

- Good vision in the eye before the incurable corneal disease.

- Good light perception and projection in the eye.

- Eye where keratoplasty stood no chance of success.

- Eye with no chance of keratoplasty being performed in the foreseeble future due to non availability of donor material.

- Patients who could emotionally withstand the possibility of failure of the surgery.

\section{Steps of the operation}

The surgical steps outlined below (A-I) were developed by Worst-Singh and van Andel

A. 360-degree peritomy of the entire conjunctiva, radial conjunctival incisions and reflection of the conjunctiva up to the equator were carried out on the eye with the diseased cornea.

B. $3 \mathrm{~mm}$ trephine was used to make an opening in the centre of the diseased cornea.

C. Two horizontal cuts were made in the trephine opening (3 and 9 o'clock).

D. The opening was widened to remove the iris, lens or any membrane that may be present. If necessary a vitrectomy was performed.

E. Two or three steel sutures (40 microns) were passed through the horizontal cuts in the trephine opening and small loops kept clear of the opening were made.

F. The prosthesis was passed through the opening and the loops of the prosthesis fixed at the equator by four interquadrantal stainless steel sutures or pre placed 80-micron fixation sutures.
G. The pre placed and knotted 40 micron sutures were tied under the anterior flange of the prosthesis, essentially completing the local fixation.

H. The conjunctival flaps were brought back and sutured so as to cover the eyeball up to the limbus.

I. Pressure was raised by infusing the anterior chamber.

When normal pressure was obtained the inter-quadrantal scleral fixation sutures were tightened and given a second knot. Post-operatively, patients were admitted for 1-2 weeks and were placed on systemic and topical antibiotic, topical steroids, a sub-conjunctival steroid, analgesic injection and anti-glaucoma medication. While on admission, VA was assessed regularly and the usual monitoring measures post intraocular surgery were ensured. Intraocular pressures could not be measured, but the patients were placed on antiglaucoma medication to be continued after discharge.

\section{RESULTS}

Patient 1 was a 76-year-old man from a city about 450 kilometres from our practice. He was a bilateral aphakic and had advanced glaucoma in both eyes. The right eye (RE) had an intracapsular cataract extraction (ICCE) and developed corneal decompensation some years later. He had light perception (LP) vision in the eye. The left eye (LE) had a cup disc ratio of about 1.0 disc cupping and vision was mere hand movement. A successful keratoprosthesis surgery in the right eye improved the vision to $6 / 48$ (best corrected). He was able to sign his cheques and read with the assistance of a hand magnifier. He visited the clinic on two occasions to shave the conjunctiva off the prosthesis. Three years later, his vision fell to $6 / 60$ with the onset of the development of a retroprosthetic membrane (RPM), which had commenced a year earlier. He was referred for YAG laser disruption of the RPM. The patient has not been seen since the referral for YAG laser.

Patient 2 was a 30-year-old male. He was bathed with acid 10 years before presentation. He had total corneal blindness and severe acid burns and scarring of the face. His visual acuity (VA) was LP in the RE and hand movement (HM) in the LE. Keratoprosthesis (KP) surgery was successfully performed on the RE. At discharge, his vision was 6/36. He failed to come for refraction at 3 months. He was seen 3 years later with a dense RPM that reduced his vision to HM. He opted to go overseas for YAG laser treatment of the RPM. However, he did not travel abroad and has not been seen since.

Patient 3 was a 36-year-old male. He was involved in a carbide explosion accident about 6 years before. The cornea in both eyes were vascularized. Vision in the LE was LP and RE was HM. The LE eye had a successful KP surgery. On 
removing the eye pad on the first day post-surgery, the patient could see the wall clock in the ward. More important was that he saw his wife's face for the first time in the 3 years of their marriage. His corrected vision VA in the LE was 6/36. The patient pleaded with us to carry out surgery on the other eye. The request was refused as we wanted to see the intermediate and long-term outcome of KP in the African eye, especially as the patient had alkaline burns. One year later, the patient developed a dense vascularized RPM. He was sent for YAG laser disruption of the RPM. This was unsuccessful as the RPM was very tough and bleeding was severe. We tried to excise the membrane invasively, but this also resulted in profuse bleeding, and the RPM could not be accessed. When seen 3 years later (4 years post-surgery), the patient had a dense RPM and vision was LP.

Patient 4 was a 54-year-old man that suffered a gun powder blast 25 years previously. Both eyes were affected. He had no light perception (NLP) vision in the RE which was completely destroyed; the LE had LP, with a disorganized anterior segment and vascularized/scarred cornea. The patient had attended a school for the blind and was now an instructor in handicraft in a school for the blind. Word got to him that he had a chance to see again. His KP surgery in the LE was a success. At two years post-surgery, his best-corrected vision was 6/36 (LE). He was able to read bold print and attend the clinic by himself. The fundus could be seen clearly having numerous chorio-retinal scars.

By the $6^{\text {th }}$ year post surgery, however, his vision began to fail. Instead of visiting the clinic, he was advised by relatives to try an instillation into his only seeing eye of a cocktail of cow urine and herbal extracts. He developed severe infective endophthalmitis and the eye could not be saved. All that the patient required was a shaving off of the epithelial overgrowth on the prosthesis that had reduced his vision.

Patient 5 was a 42-year-old male (a commercial motorbike rider) who was attacked with a concentrated mixture of formalin and sulphuric acid. The LE was destroyed (NLP); the RE was LP with a vascularized and scarred cornea; the anterior segment was severely disorganized. He had a successful KP surgery a year after the attack and his VA was $6 / 9$ after correction. He was able to resume his trade as a commercial motorbike rider. At 15 months post surgery, the patient had pars planitis that got us worried, and we suspected retinal detachment. An ultrasound scan suggested retinal detachment. The patient was referred to a vitreo-retinal centre that believed the retina was intact. The patient recovered after steroid medications and his vision was about $6 / 9$ again. At 4 years post surgery, the patient started to develop RPM and his vision fell to 6/60. The patient was referred for YAG laser treatment of the RPM. He delayed the laser therapy for 2 years; by then his vision became HM, and YAG laser could not be used to reduce the RPM. The RPM had to be surgically excised, after which his vision improved to count fingers $(\mathrm{CF})$, less than a metre.

\section{DISCUSSION}

The Corneal Grafting Act of 1993 empowered corneal grafting in Nigeria. ${ }^{10}$ Corneal transplant is the most successful tissue transplant surgery in the world today, however, this surgical procedure is practically non-existent in the developing world, Nigeria inclusive. The major limiting factors include lack of skilled personnel, storage facilities and donor materials. This situation has consigned many Nigerians whose sight could have been corrected to schools for the blind or to living as beggars on the street. ${ }^{8}$ The authors of this report attempted to address the situation in Nigeria by offering the keratoprosthesis procedure.

The initial outcome of KP in the first five Nigerian eyes was satisfactory. The patients could see again. In the first 3 years, those who had retroprosthetic membrane (RPM) had satisfactory vision (table 1); the only case of uveitis was successfully managed. Three to six years afterwards, four of the five eyes had their vision significantly reduced by dense RPM and one became completely blind (NLP) from endophthalmitis (table 1). The retroprosthetic membrane (RPM) formation started from 24 months (table 1). This discouraging mid-term outcome has led to the suspension of further keratoprosthesis surgery until something can be done to reduce RPM. It was observed that the eyes that had very severe inflammation (alkaline or acid burns) developed RPM earlier than eyes that had corneal problems such as decompensation from cataract surgery; the finding is similar to that of Yaghonti et al. ${ }^{11}$ Four out of the five eyes developed RPM under six years. The fifth eye had severe endophthalmitis that made the eye phthysical, but he had no RPM before his endophthalmitis at six years post-operation.

The fourth patient perhaps had the best prognosis as he had no RPM by the sixth year post-surgery. However, he lost his eye from the application of a harmful cocktail of herbal extracts and cow urine, when he had a complication of epithelial overgrowth on the prosthesis, which made it water tight and which could easily have been managed by shaving it off the optical part of the keratoprosthesis.

Retroprosthetic membrane is the seemingly insurmountable complication encountered in keratoprosthesis surgery, that brought joy and later sadness to the first 5 consecutive Nigerians that had this procedure. The nature of the RPM was that it became very tough and completely vascularized to the extent that it become impervious to YAG laser disruption. Severe bleeding into the vitreous was usually the result of any determined attempt to laser the RPM. 


\begin{tabular}{|c|c|c|c|c|c|c|c|c|}
\hline Corneal problem & $\begin{array}{l}\text { Duration of } \\
\text { implant } \\
\text { (early report) }\end{array}$ & $\begin{array}{l}\text { Complications } \\
\text { at } \\
\text { early report }\end{array}$ & $\begin{array}{l}\text { Period before } \\
\text { complication } \\
\text { s started }\end{array}$ & $\begin{array}{l}\text { Vision before } \\
\text { post surgery } \\
\text { complication }\end{array}$ & $\begin{array}{l}\text { Vision after } \\
\text { complication } \\
\text { (early report) }\end{array}$ & $\begin{array}{l}\text { Treatment of } \\
\text { complication }\end{array}$ & $\begin{array}{l}\text { Vision after } \\
\text { treatment } \\
\text { (early } \\
\text { report) }\end{array}$ & $\begin{array}{l}\text { Outcome } \\
\text { 3-6 yrs after } \\
\text { surgery }\end{array}$ \\
\hline $\begin{array}{l}\text { 1. Corneal } \\
\text { decompensation }\end{array}$ & 48 months & $\begin{array}{l}\text { Conjunctival } \\
\text { over growth, } \\
\text { dense RPM }\end{array}$ & 24 months & 6.48 & $6 / 60$ & $\begin{array}{l}\text { referred to } \\
\text { YAG laser }\end{array}$ & $\begin{array}{l}\text { not seen } \\
\text { again }\end{array}$ & $\begin{array}{l}\text { DRM } \\
\text { at } 3 \text { yrs } \\
\text { VA: } 6 / 60\end{array}$ \\
\hline 2. Acid burns & 45 months & Dense RPM & 38 months & $\begin{array}{l}6 / 36 \\
\text { uncorrected }\end{array}$ & $\begin{array}{l}\text { faint hand } \\
\text { movement }\end{array}$ & $\begin{array}{l}\text { referred to } \\
\text { YAG laser }\end{array}$ & $\begin{array}{l}\text { not seen } \\
\text { again }\end{array}$ & $\begin{array}{l}\text { D R M } \\
\text { at } 3 \text { yrs } \\
\text { VA - HM }\end{array}$ \\
\hline 3. Alkaline burns & 19 months & Dense RPM & 36 months & $6 / 36$ & $\begin{array}{l}\text { hand } \\
\text { movement }\end{array}$ & $\begin{array}{l}\text { failed YAG } \\
\text { laser/ failed } \\
\text { surgery }\end{array}$ & LP & $\begin{array}{l}\text { DVRM at } \\
4 \text { yrs } \\
\text { VA: LP }\end{array}$ \\
\hline 4. Blast injury & 8 months & nil & 12 months & $6 / 36$ & $6 / 36$ & Nil & $6 / 36$ & $\begin{array}{l}\text { Endophthal } \\
\text {-mitis } \\
\text { at } 6 \text { yrs } \\
\text { VA: NLP }\end{array}$ \\
\hline $\begin{array}{l}\text { 5. Chemical burn } \\
\text { (formalin) }\end{array}$ & 7 months & uveitis & nil & 39607 & $6 / 60$ & $\begin{array}{l}\text { steroids \& } \\
\text { antibiotics }\end{array}$ & 39607 & $\begin{array}{l}\text { DVRM } \\
\text { at } 6 \text { yrs } \\
\text { VA: CF }\end{array}$ \\
\hline
\end{tabular}

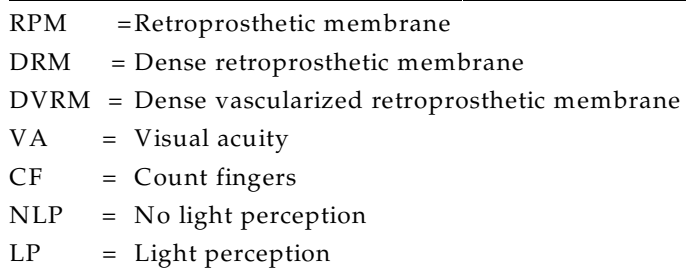

What measures were taken to prevent RPM? A high dose of steroids was given for at least 3 months, including subtenon depo methyl prednisolone injection. High doses of steroids, however, could result in corneal melt or a wound leak at the trephine site. It could also cause glaucoma in an eye in which the IOP cannot be measured.

RPM has been reported by other workers implanting comparable keratoprosthesis ${ }^{11}$ (though not in African eyes). These workers did not report or describe the membrane as being very tough and completely vascularized. Jahne $\mathrm{MG}^{12}$ categorized the RPM they encountered as a non-severe intraocular complication. ${ }^{13}$ The known excessive reaction of African eyes to trauma, ${ }^{14}$ including surgery, and the high prevalence of keloids and hypertrophic scars in Africans ${ }^{15,16}$ may be the aggravating factors here.

\section{CONCLUSION}

A way has to be found around the unusually tough and vascularized RPM in African eyes. RPM is a major impediment in restoring sight to Nigerians/Africans who cannot afford penetrating keratoplasty or achieve a successful penetrating keratoplasty because of a scarred cornea or a disorganized anterior segment. The intermediate-term outcome using the Worst-Singh keratoprosthesis in five
Nigerian eyes has shown it to be unsuitable for now, because of the problem posed by the tough and vascularized retroprosthetic membrane.

\section{REFERENCES}

1. Singh D, Worst J, Singh I. Cataract and IOL 1993. $1^{\text {st }}$ ed Amristar 1991: 264-267.

2. Pine D. Restoring vision through keratoprosthesis. PES Journal 1997; 17(3): 10-11.

3. Pavel JM. 200 years of keratoprosthesis: Pellier de Quengsy and the artificial cornea. Anales del Instituto Barraquer 1999; 28: 33-41.

4. De Quengsy PG. Précis ou Cours d'Opérations sur la Chirurgie des Yeux. Paris: Didot. 1789.

5. Van Andel MV, Worst J, Singh I. Artificial corneas for the third world. Anales del Instituto Barraquer 1999; 28: 177-179.

6. Renard G. Artificial cornea. Bull Acad Natl Med 1996; 180(3): 665668.

7. Osahon AI. Consequences of traditional eye medication in UBTH, Benin City. Nig J Ophthalmology 1995; 3(2): 51-54.

8. Abiose A, Murdoch I, Babalola O E. Distribution and aetiology of blindness and visual impairment in mesoendemic onchocercal communities: Kaduna State of Nigeria. $\mathrm{Br} \mathrm{J}$ Ophthalmol 1994; 18(1): 8-13. 
9. Waziri-Erameh MJM, Omoti AE. Keratoprosthesis: Hope for the hopeless corneal blind. Nig J Ophthalmology 2001; 9(1): 28-31.

10. Laws of the Federal Republic of Nigeria: Corneal Grafting Act of 1993; Cap 69: 3053-3054.

11. Yaghouti F, Nouri M, Abad JC, Power WJ, Doane MG, Dohlman CH. Keratoprosthesis: Pre-operative prognostic categories. Cornea 2001; 20(1): 19-23.

12. Jahne MG. 25 years cardona keratoprosthesis after severe chemical eye burns: Long term outcome of 4 eyes. Klin Monatsbl Augenheikd 2000; 216(4): 191-196.

13. Blumenthal M. Corneal keratoplasty in Tanzania $A m$ J Ophthalmol 1968; 65: 762-768.
14. Welsh N. H. Failure of filtering operations in African eyes. Br J Ophthalmol 1970; 54: 594-598.

15. Ketchum LD, Cohen IK, Masters FW. Hypertrophic scars and keloids. A collective review. Plast Reconstr Surg 1974; 53: 140145.

16. Rockwell WB, Cohen IK, Ehrlick HP. Keloids and hypertrophic scars. A comprehensive review: Plast Reconstr Surg 1989; 84: 827-837. 